to be expected from Raoult's law. This might be ascribed to association of the atoms of the solute. It is shown, however, that the deviation of the pressures from Raoult's law are due to the abnormal properties of the system under consideration. From the form of the complete vapor pressure curve of sodium solutions, it appears that the deviation is due to the fact that there is a tendency for the solutions to separate into two phases for which the critical point lies near 3 molal per cent. of metal. That separation takes place in this region at lower temperatures has been shown in an earlier paper. The law of Raoult can not, therefore, be applied to solutions more concentrated than o. I normal.

Boston, June 9, 1908 .

\title{
THE DETERMINATION OF VAPOR PRESSURES OF SOLUTIONS WITH THE MORLEY GAUGE.
}

\author{
By O. F. TowER. \\ Received June 6, 1908.
}

Vapor pressures of liquids were first measured by the static method, which consists essentially in introducing the liquid under investigation into the Torricellian vacuum of a barometer and noting the distance the mercury column falls. ${ }^{1}$ Many accidental and almost unavoidable circumstances render this method uncertain, so that within recent years it has been but seldom employed. Many other methods have replaced it. In one, an indirect method developed by Ramsay and Young, ${ }^{2}$ the vapor pressure of a solution is calculated from observations of its boiling point under different pressures.

The methods, however, used most commonly, recently, divide themselves into two classes, which may be designated as the "differential" and the "dynamic" methods. In the "differential" method the difference between the two vapor pressures, commonly that of a pure solvent and one of its solutions, is measured by means of a suitable gauge. Dieterici $i^{3}$ employed as a gauge a membrane connected with a pointer; any difference in pressure on the two sides of the membrane would cause a movement of the pointer which could be read off on a scale. Smits employed a so-called "micromanometer" based upon the principle that if a $U$ tube, whose upper portions are considerably widened so that they have a diameter $n$ times that of the lower portion, is filled with a liquid, any movement of the level in the upper portions produces a movement of $n$ times the distance in the lower. It is of course necessary to have a visible meniscus in the lower portion of the tube. This was accom-

${ }^{1}$ See Magnus: Pogg. Ann., 38, 93 (I836).

${ }^{2}$ Phil. Trans., A I83, 107 (1892).

${ }^{3}$ Wied. Ann., 50, 47 (1893); 62, 616 (1897); and 67, 859 (1899).

${ }^{4} Z$. physik. Chem., 39, 385 (1902). 
plished by filling the tube with superimposed non-miscible liquids. The upper liquid must also be practically non-rolatile. Smits used aniline, water and olive oil in his apparatus.

The "dyamic" method was first used by Regnault ${ }^{1}$ in 1845 and is based upon the principle that when air or some other inactive gas is saturated with the vapor of the liquid or solution the following relation holds:

the total volume

the total pressure

the volume of the aqueous vapor $=$ the pressure of the aqueous vapor

The vapor pressure may therefore be obtained from the total volume, the total pressure and the amount of acuteous vapor. Ostwald ${ }^{2}$ simplified this method greatly by allowing the air first to bubble through the solution and then through pure water. The ratio $\frac{p-p^{\prime 3}}{p^{\prime}}$ - is what is usually sought, and this is given directly by the above process, since $\frac{\text { the loss in weight of the water }}{\text { the loss in weight of the solution }}=p-p^{\prime}$. liron the vapor pressure of water in the tables, that of the solution may also be obtained with the same data. This method has also been very recently improved by Kahlenberg ${ }^{4}$ and by the Earl of Berkeley and Mr. Hartley. ${ }^{5}$

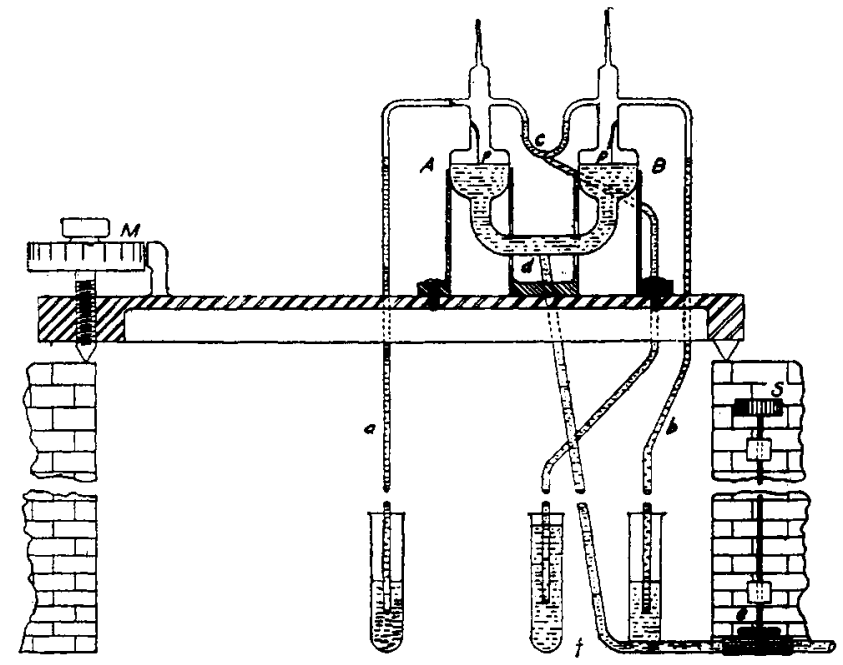

Fig. I.

1 Ann. chim. phys. [3], I5, 129 (1845).

2 This method was used by Walker, $Z$. physik. Chem., 2, 602 (1888).

${ }^{3} p$ represents the vapor pressure of pure water and $p^{\prime}$ of the solution.

4 Science, 22, 74 (1905); see also Lincoln and Klein, J. Phy's. Chem., I1, 31 8 (1907).

5 Proc. Roy. Soc., A 77, I 56 (1906). 
The method, however, with which we are concerned here belongs to the "differential" class and is very similar to that of Smits except that his micromanometer is replaced by a mercury gauge designed by Morley ${ }^{1}$ for the measurement of small differences of pressure. This gauge is shown in Fig. I. Fig 2 shows the central U-tube portion while in process of construction. Platinum wires $p_{1} p_{2}$ with carefully shaped points are fused into the sides of the limbs $A B$, so that they hang at the same level. ${ }^{2}$ This part of the apparatus is then mounted before a double telescope cathetometer. The telescopes are directed through $C$ and $D$, respectively, directly on the points of the platinum wires. The distance between these points is thus accurately determined. In this apparatus it amounted to $157.15 \mathrm{~mm}$. $C$ and $D$ are then closed by fusing off the glass. These tubes are then securely mounted in two brass cylinders

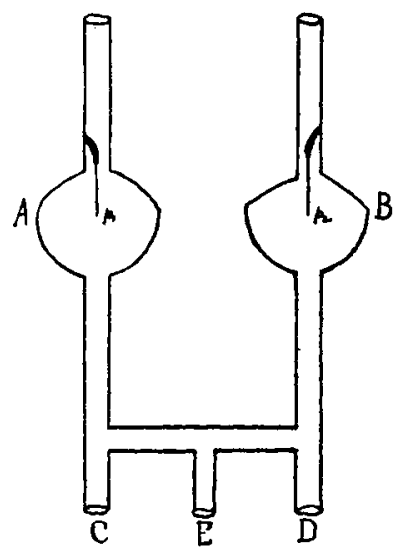

Fig. 2, by means of plaster of Paris, and the cylinders soldered on the base to a heavy piece of brass, which is mounted upon the iron beam shown in Fig. I. The beam rested upon a recessed brick pier. On top of the pier were cemented two heavy glass plates. The beam rested on one of these (at the right) by means of two points and on the other by means of a micrometer screw. Guard rings held the points in position.

By means of a spirit level it was found that one revolution of the micrometer screw was equivalent to $2^{\prime}, 45^{\prime \prime}$. The length of the beam between the points of support is $616.2 \mathrm{~mm}$., and the distance between the screw threads is $0.505 \mathrm{~mm}$., whence the angular movement for one revolution is found to be $2^{\prime}, 49^{\prime \prime}$. The average of these two values, $2^{\prime}$, $47^{\prime \prime}$, was the value used in calculating the results. The tube $d f$ was connected with a thick-walled piece of rubber tubing which passed under $e$ and then to a resevoir of mercury. On evacuating the apparatus mercury was drawn into the gauge, and when it had reached the proper height, the glass tube was sealed off at the right of $e$. The screw $S$ pernits the adjustment of the mercury level at $A B$. Through the tubes $a b$ additional mercury could be introduced into the gauge. At $c$ is a mercury valve for closing communication between $A$ and $B$.

The portion of the apparatus shown in Fig. I was connected with Morley.

' $A m$. J. Sci., 13, 455 (1902). The form used here was the one designed by

8 The bulbs are about $70 \mathrm{~mm}$. in diameter, while the tubes above and below are $8 \mathrm{~mm}$. 
the rest of the apparatus by means of the two vertical tubes at the top. These were bent over and joined to $a$ and $b$, Fig. 3. In this figure $D$

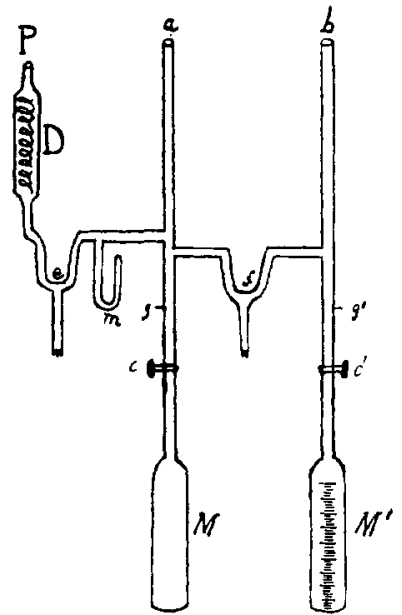

Fig. 3. is a large drying tube containing phosphorus pentoxide on glass wool. $P$ leads to the mercury pump. $m$ is a small manometer. $e$ and $f$ are mercury valves. $M$ and $M^{\prime}$ are tubes of Jena glass holding about $100 \mathrm{cc}$, in which are contained the pure solvent and the solution. () $M^{\prime}$, the one containing the solution, was a millimeter scale. The tube was calibrated with mercury, so that the readings on the millimeter scale gave at once the volume of the solution. Since the pure solvent was always in $M$, its vapor pressure could be readily obtained at the temperature of the experiment by observation with a cathetometer of the manometer at $m$ (see p. 1228).

The manner of getting the liquids into $M$ and $M^{\prime}$ was as follows: The tubes $M$ and $M^{\prime}$ were first sealed to glass stop-cocks, Fig. 4 . Since the tubes were of Jena glass and the stop-cocks soft glass, this was a matter of considerable difficulty. The joint $h$ was of lead glass, such as is specially prepared for fusing together different kinds of glass. Even then this was the weakest part of the apparatus, and was a continual source of annoyance and delay by frequently coming apart. After attachment to the cock and proper cleaning, the liquid was introduced into the tube through a long funnel. The end at $g$ was then connected with a powerful water pump, and the liquid boiled under reduced pressure until the air was expelled. The stop-cock ${ }^{1}$ was then closed and the tube fused to the main apparatus, $g$ and $g^{\prime}$, Fig. 3 , after which the apparatus was evacuated through $P$. After opening the stop-cocks $c$ and $c^{\prime}$, evacuation was continued. This was, however, only a precaution, as $M$ and $M^{\prime}$ were usually found to be entirely free from air. The tubes $M$ and $M^{\prime}$ were submerged in a

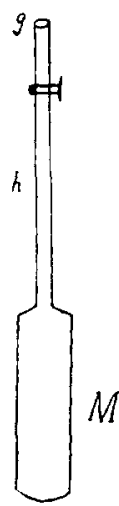

Fig. 4 . water bath at a little below room temperature, about $15^{\circ}$, in the preliminary experiments; in the later experiments they were packed in ice. After standing thus for 4 to 6 hours, valve $e, r i g .3$, was closed and measurements were made. These measurements were repeated at various intervals, $M$ and $M^{\prime}$ being frequently shaken in the meantime.

The method of making a measurement with the gauge is thus described

1 These stop-cocks were lubricated with Guye's preparation, which is non-volatile at ordinary temperatures; see $\mathrm{J}$. chim. phys., 3, 556 (I905) 
by Morley and Brush:" "We must first determine the reading of the micrometer when the pressure in $A$ and $B$ has been made the same by putting them in free communication by the mercurial valve $c$, Fig. I. We turn $M$ till the depressions made by the two points in $A$ and $B$ seem equal. Then we lessen the compression of $e$ and so lower the level of the mercury in $A B$ till one of the depressions is barely perceptible. These two steps are repeated; we equalize and then reduce the depressions till they are equal when made the minimum visible. The reading of $M$ is then the reading for equality of pressure in $A$ and $B . "$

"The method of comparing the depressions needs no optical assistance. The observer places himself so as to see the image of a horizontal windowbar reflected by the two mercury surfaces. Moving his eye so as to cause the image to pass across the depressions, their dimensions are easily compared. As they are made smaller by lowering the level of the mercury, the error of comparison becomes smaller. When they are barely visible, this error may easily be made less than $0.0002 \mathrm{~mm}$; after some practice, of course."

Having determined the reading for equality of pressure, the valve $c$ is closed, as also the valve $f$, Fig. 3 , and the reading made exactly as before. The difference in the reading of the micrometer screw is thus given, and from this and the distance between the points, the difference in the level of the mercury is easily calculated. The head of the micrometer screw is divided into soo parts, and since the angles of inclination are always small, the difference of the micrometer readings needs only to be multiplied by a constant factor to give the difference in level of the mercury in $A$ and $B$ in millimeters. In this apparatus for one division on the head of the micrometer screw, the factor is 0.0012724 .

All solutions were prepared from c. p. chemicals, which were also subjected to recrystallization before being used. The solutions were sometimes diluted by removing the tube $M^{\prime}$ and adding distilled water. After boiling out under reduced pressure the new volume was read off on the millimeter scale. The analysis of all solutions was carried out by evaporating an aliquot portion to dryness and weighing the residue. In the case of all the more concentrated solutions, the density was also determined so that the concentration could be expressed on the basis of a definite weight of water rather than on a definite volume of the solution.

Raoult ${ }^{2}$ in his early work formulated the connection between the relative lowering of the vapor pressures and the molecular constants of the solution as follows:

1 Loc. cit., p. 456 .

$$
\frac{p-p^{\prime}}{p}=\frac{n}{N}
$$

Compt. rend., 87, 167 (1878). 
Here $p$ and $p^{\prime}$ have the same significance as before, $n$ is the number of moles of solute dissolved in $N$ moles of solvent. $\mathrm{He}^{1}$ later, however, found the following equation to accord more nearly with the facts:

which reduces to the form,

$$
\frac{p-p^{\prime}}{p}=\begin{gathered}
n \\
n+N
\end{gathered}
$$

$$
p-p^{\prime}={ }^{n}
$$

From this the molecular weight $m$ of the solute is given by

$$
m=\frac{q M}{p \cdots-p^{\prime}}
$$

in which $M$ is the molecular weight of the solvent and $g$ is the number of grams of solute in I gram of solvent. The same equation may be derived from Lewis' law of ideal solutions in his recent paper on the "Osmotic Pressure of Concentrated Solutions." It would probably be more nearly correct theoretically to write the equation for concentrated solutions in the form,

$$
m=\frac{u m}{\ln \frac{1}{p} ; 3}
$$

for in the rigorous derivation of the equation between the osmotic pressure and the relative lowering of the vapor pressures, ${ }^{4}$ the relative lower-

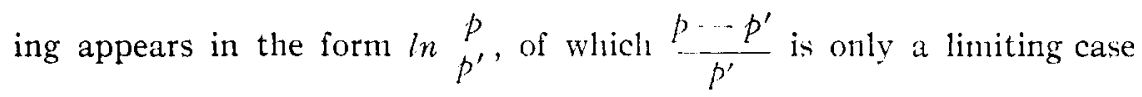
when the solution is dilute. In dilute solutions, therefore, both equations give the same value for the molecular weight. Even in concentrated solutions the equations do not lead to very divergent values, as the following results with solutions of cane sugar show. The first set of values are Smits's ${ }^{5}$ obtained with the differential micromanoneter, the second set is taken from the paper of Lord Berkeley and Hartley, ${ }^{\text {" while the }}$ third set are preliminary measurements made by myself while testing the apparatus.

'Z. physik. (hem, 2, 353 (I88s).

2 This Journal, 30, 668 (1908). See equation (5), p. 674.

${ }^{9} l n$ indicates natural logarithms.

"See Walker, "Introduction to Physical Chemistry" $4^{\text {th }}$ Iid., D. 37t-2; also Nernst, "Theoret. Chemie," 5 te Auflage, p. I.3s'.

Loc. cit., Pp. 397 and 402.

B Loc, cit., p. 165. 'The result of Dec, 8, June I9, and Oct 6 are the ones selected as best representing the average at each concentration. 
Sugar in 1000 gm. water.

(1)

(2)

(3)

$\begin{array}{rr}66.05 & 15.5 \\ 256.67 & 15.0 \\ 342.22 & 15.0\end{array}$

I 55.40

266.63

345.27

644. I0

$345.65^{1}$

567.72

I 123.36 $0.0^{\circ}$

Temp. $\quad p-p^{\prime}$.

" 0.06485

o. 09074

o. 1745

18. 3

I4. 2

15.5

5.0

15.0 $\ldots{ }^{2}$

$\ldots$

...

0.047

o. 172

o. 234
19.0

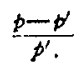

$\ln \frac{p}{p^{\prime}}$

0.008704

o. 01425

0.02001

0.03884

0.03962

0.02040

0.03514

o. 08235

o. 003597

0.01373

o. 01877

0,02019

0.03454

o. 07912

0.00359 I

$\begin{array}{cc}m_{1} . & m_{2} . \\ 319.7 & 321.4 \\ 334.1 & 336.7 \\ 307.4 & 310.6 \\ 292.6 & 298.5\end{array}$

305.0

308. I

290.8

295.9

$245.6 \quad 255.6$

$m_{1}$ is the molecular weight calculated from equation ( $\mathrm{I}$ ), and $m_{2}$ from equation (2). Although the difference between them is not great, the second shows a closer approximation to the true molecular weight (342.2) than the first. There is an unmistakable tendency, however, for the calculated molecular weight to decrease as the concentration increases. This has also been noticed when the molecular weight has been determined by other methods. ${ }^{3}$ Lord Berkeley and Hartley's results for the vapor pressures of the solution are undoubtedly too low, showing probably that with their apparatus the air was not completely saturated with aqueous vapor after passing the solution. Carveth and Fowler ${ }^{4}$ and Lincoln and Klein ${ }^{5}$ emphasize this difficulty in the employment of the dyamic method, and seem to have overcome it successfully by first supersaturating the air with water vapor before it passes through the solution.

The principal results which I have to present were obtained with solutions of the two salts, $\mathrm{KI}$ and LiCl, one of which is typical of anhydrous salts and the other of hydrated salts. All the measurements were made at $0^{\circ}$, the tubes $M$ and $M^{\prime}$, Fig. 3, being packed in ice. The vapor pressure of pure water at this temperature was taken as $4.579 \mathrm{~mm}^{6}$ The results are given in the accompanying table.

'The density of the two most dilute solutions of potassium iodide was not determined. The concentration of both substances was carried practically to the point of saturation. The numbers under $m$ were cal-

1 Calculated from the volume normal concentrations of the original by means of the densities of sugar solutions given in Landolt, Börnstein and Meyerhoffer, Tables, p. 364 .

${ }^{2} p-p$ ' was not directly obtained by this method.

${ }^{3}$ See Raoult, Z. physik. Chem., 27,653 (1898). Kahlenberg, J. Phys. Chem., 5, 377 (Igor).

1. Phys. Chem., 8, 3г3 (1904).

'Ibid., 11, 333 (1907).

- Landolt, Börnstein and Meyerhoffer, Tables, p. I Ig. 
culated by means of equation (1), $\Lambda$ few values are given for lithium chloride under $m_{1}$ calculated from equation (2).

POTASSIUM IODHE IN WATER.

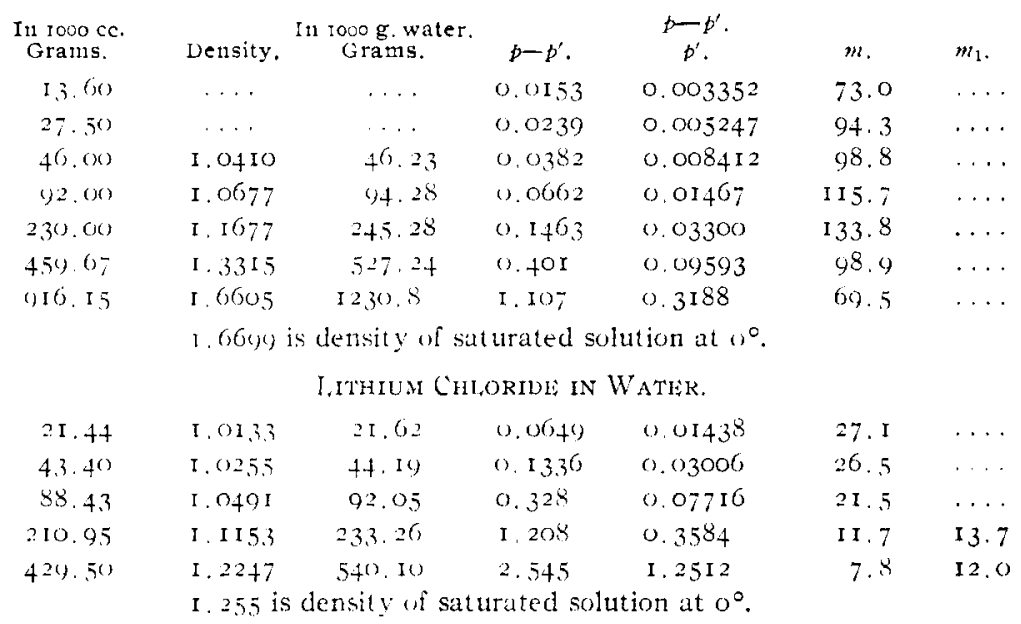

In the case of potassium iodide the calculated molecular weight first increases with the concentration and then decreases. The increase with the concentration is what one would expect according to the dissociation theory. The decrease shown with the concentrated solutions and with lithium chloride is in accord with what was observed with solutions of cane sugar at high concentrations. These facts are in line with much other experimental evidence and simply go to prove what has been known for a long time, that the dissociation theory does not hold in concentrated solutions, nor should it be expected to hold in such solutions where the heat of dilution is undoubtedly not zero. The continued decrease in the calculated molecular weight of lithium chloride may be associated with its tendency to form hydrates, although the existence of definite hydrates in solutions would in itself lead to larger rather than smaller molecular weights. Similar behavior was observed by Lincoln and Klein with regard to the vapor pressure of lithium nitrate solutions. This substance forms no hydrates when it crystallizes from warm solutions, but does at lower temperatures. It is the fashion at the present time to ascribe almost all "abnormal" behaviors of solutions to the existence in them of definite hydrates. Most of the arguments on this point, lowever, beg the question, so that it is of little advantage to insist upon this extreme view, viz, the existence of definite hydrates; yet it may be worth while to suggest that the attraction of the solute for water tends to hold back some of the water molecules from entering the vapor state and hence the vapor pressure may be depressed more 
than in the case of substances which form no hydrates. Such a tendency would of course increase with the concentration.

This method of determining differences of vapor pressure with the Morley gauge is apparently very accurate as far as the measuring apparatus goes. The sources of error and chief difficulties lie elsewhere. Chief among these was the presence of the two stop-cocks, which I did not see my way clear to dispense with and which were a constant source of apprehension. Whether the tubes in the bath were shaken more or less seemed to make but little difference; but what the effect of the violent agitation attained in the dyamic method might be is unknown. The hygroscopic properties of the walls of the glass tubing may have had some effect, but it hardly seems probable that this effect could be great. At any rate the readings varied a good deal, so that it was necessary to make a great number of measurements and take the average. The time consumed in doing this and the still greater amount consumed in repairing breaks and other troubles is so annoying that the method is scarcely one to be unhesitatingly recommended. The dyamic method seems to be an improvement over this one in all the points enumerated and also is to be preferred, since measurements can be made at any temperature. In the method here described the solutions must always be kept at a temperature considerably lower than that of the gauge.

Measurements of the vapor pressures of some non-aqueous solutions were attempted. The solvents employed were methyl and ethyl alcohols, and the solutes were tetrethylammonium iodide, potassium iodide and lithium chloride. The alcohols were pure specimens; they were kept over lime for several weeks and then distilled directly into the measuring tubes.

The readings with the gauge fluctuated much more than in the case of aqueous solutions. This may have been due to the lubricant used on the stop-cocks, which was soluble in alcohol. It must therefore have had some effect upon the vapors of the alcohols and hence also upon their vapor pressures. Averages of several readings were, however, taken, and the results so obtained are given in the table.

SOLVENT: METHYL, Al,COHOL.

In $1000 \mathrm{cc}$. Grams.

3.425

6.731

I 2.84

8,28

I6. 60

2. 60

9.80

$$
p-p^{\prime}
$$$$
\frac{p-p^{\prime}}{p^{\prime}}
$$

Solute, Tetrethylammonium iodide.

$$
\begin{array}{ll}
0.038 & 0.00128
\end{array}
$$

o. 104

o. 198

$0,0035 \mathrm{r}$

$0,0067 \mathrm{r}$

Solute, Potassium iodide.

o. 0827

o. 00279

o. 2290

0.0777

Solute, Irithium chloride. $m$.

86.2

$6 \mathrm{I} .3$

$6 \mathrm{I} .2$

94.9

68.4

2 I. 4

18. 9 
Solvent: Ethyl Alcohol.

\begin{tabular}{|c|c|c|c|}
\hline \multirow[t]{2}{*}{$\begin{array}{l}\text { In tooo cc. } \\
\text { Grams. }\end{array}$} & $p-p^{\prime}$ & $\begin{array}{c}p-p^{\prime} \\
p^{\prime}\end{array}$ & $m$ \\
\hline & ite, 'Tetr & ium iodid & \\
\hline 3.68 saturated & $\begin{array}{l}0.023 \\
\text { Solute, }\end{array}$ & $\begin{array}{l}0.00185 \\
\text { dide. }\end{array}$ & $9 \mathbf{I}, 7$ \\
\hline 3.06 & 0.0191 & 0.001 .53 & 91.9 \\
\hline 7.12 saturated & 0.0662 & 0.00 .533 & 61.4 \\
\hline \multicolumn{4}{|c|}{ Solute, I, it hium chloride. } \\
\hline 8.56 & $0,1,3,3$ & 0.01077 & 36.6 \\
\hline 20.59 & (1).323 & 0.02657 & 3.5 .6 \\
\hline IOI.03 & (1). (x) 2 & (1).018615 & 53.9 \\
\hline
\end{tabular}

The values with tetrethylammonium iodide and the last one with lithium chloride seem to be far from correct. Why they should be less trustworthy than the others, I am, however, unable to say.

One actual accomplishment in connection with these determinations was the determination of the vapor pressures of pure methyl and ethyl alcohol at $o^{\circ}$. These values were obtained by observation of the manometer $m$, Fig. 3, with a cathetometer. To obtain trustworthy readings it was necessary to tap the manometer several times before making an observation. The results of these determinations are given below. The averages were used in the table above in calculating the numbers in the third column.
Methyl alcohol.
mim.
Fithyl alcohol.
29. 4.5
$\mathrm{mm}$.
29. (40)
L 2.55
29). 55
I 2.45
20.00
โ2. 25
12.60
Average, 29.70
$\mathrm{I} 2.48$

Previous determinations of these quantities have resulted as follows:

$\begin{array}{cl}\begin{array}{c}\text { Vapor pressure. } \\ \text { mm. }\end{array} & \text { Methyl alcohol. } \\ 26.82 & \text { Authority } \\ 29.7 & \text { Degnault } \\ & \text { Ditimar and Fawsit t }\end{array}$

\begin{tabular}{cl}
$\begin{array}{c}\text { Vapor pressure. } \\
\text { mn. } \\
12.70\end{array}$ & \multicolumn{1}{c}{ Authority. } \\
Regmault \\
2.24 & Ramsay and Young
\end{tabular}

In conclusion, it may be said that the differential method of determining vapor pressures by means of a gauge appears to be less trustworthy and subject to more limitations than the dynamic or air-bubbling method, when the latter is carried out with suitable precautions.

WESTERN RESERVE UNIVERSITY,

Cleveland, Ohlo,

'I.andolt, Bürustein and Meyerhofier, Tables, p. I.39. 